\title{
Hot Wire-Assisted Gas Metal Arc Welding of Ni-Based Hardfacing
}

\author{
The degradation behavior and distribution of fused tungsten carbides were \\ influenced by applying an additional hot wire
}

BY K. GÜNTHER, J. P. BERGMANN, C. ZHANG, M. ROSENBERGER, AND G. NOTNI

\begin{abstract}
For the deposition of Ni-based hardfacings reinforced with fused tungsten carbides (FTCs), a variety of manufacturing processes are industrially applied. Of these processes, plasma transferred arc welding (PTAW) and gas metal arc welding (GMAW) are most widely used. The primary advantages of GMAW are the controlled feeding of the filler material in terms of the flux cored wire, the uncomplicated use on site, and the high mechanical degree. However, GMAW is known to have a negative impact on the metallurgical properties of FTCs for several reasons; for example, FTCs are directly exposed to the high arc temperatures, promoting dissolution mechanisms, and increasing deposition rates are accompanied by a rising heat input. A new GMAW strategy was developed with the objective of separating the material and energy input. The application of an additional hot wire (HW-GMAW) was observed to remove heat from the melt pool. As a result, low dilution rates of $\sim 5 \%$ were obtained for deposition rates of $\sim 12 \mathrm{~kg} / \mathrm{h}$, approaching PTAW quality. Additionally, the modified process characteristics have an immediate impact on the characteristics of FTCs.
\end{abstract}

\section{KEYWORDS}

- Hot Wire • GMAW • Hardfacing • Fused Tungsten Carbides

\section{Introduction}

To improve the wear resistance of tools for mining and oil drilling applications, Ni-based alloys reinforced with hard phases are widely used in the hardfacing process. The hard phases act as obstacles against the penetrating abrasive, positively affecting the abrasive wear performance. As hard phases, W-rich carbides, such as metastable $\mathrm{WC}_{(1-\mathrm{x})}$ and fused tungsten carbide (FTC), are of high importance as hardfacing materials (Refs. 1, 2).
The high abrasive wear resistance of FTCs is attributable to the microstructure, characterized by a eutectoid morphology of mono-tungsten carbide (WC) and di-tungsten carbide $\left(\mathrm{W}_{2} \mathrm{C}\right)$ (Ref. 3). The benefit of this microstructure is a combination of high hardness and fracture toughness, exceeding the tribological properties of other commercially available hard phases (Ref. 4). However, high cooling rates are necessary during the manufacturing process to stabilize the high temperature phase $\mathrm{W}_{2} \mathrm{C}$ below $\sim 1200^{\circ} \mathrm{C}$ and to ensure the presence of both phases at room temperature (Refs. 2, 3, 5, 6). Consequently, welding of FTCs poses a challenge because high thermal loads promote the dissolution of the phase $\mathrm{W}_{2} \mathrm{C}$ according to equation No. 1 (Refs. 2, 3):

$$
W_{2} C \rightarrow W C+W
$$

Hence, FTCs require a controlled heat input during welding to counteract a thermally induced dissolution, leading to a decrease in FTC content and the formation of brittle $\mathrm{W}$-rich precipitations in the matrix (Ref. 7). As a result, the wear resistance of the hardfacing decreases (Refs. 8-10). A further challenge is the segregation behavior of FTCs in the liquid melt caused by density differences (Refs. $11,12)$. In this context, a homogeneous distribution of hard phases is intended to achieve maximum wear resistance properties.

For the deposition of FTCreinforced Ni-based hardfacings, a variety of manufacturing processes are used, of which plasma transferred arc welding (PTAW) and gas metal arc welding (GMAW) are the most common (Ref. 13). The primary advantages of GMAW are the controlled feeding of the consumable electrode in terms of flux cored wire, the uncomplicated use on site, and the high mechanical degree (Ref. 14). However, GMAW process 


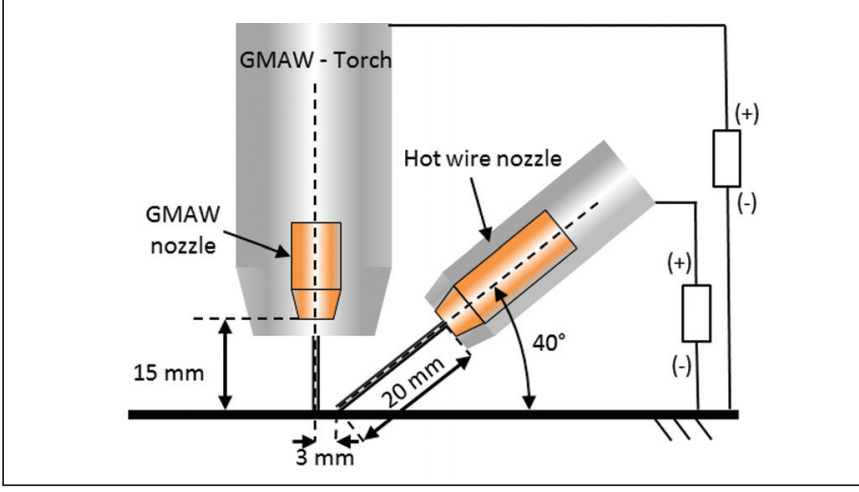

Fig. 1-Schematic of the experimental setup for hot wireassisted gas metal arc welding (HW-GMAW).

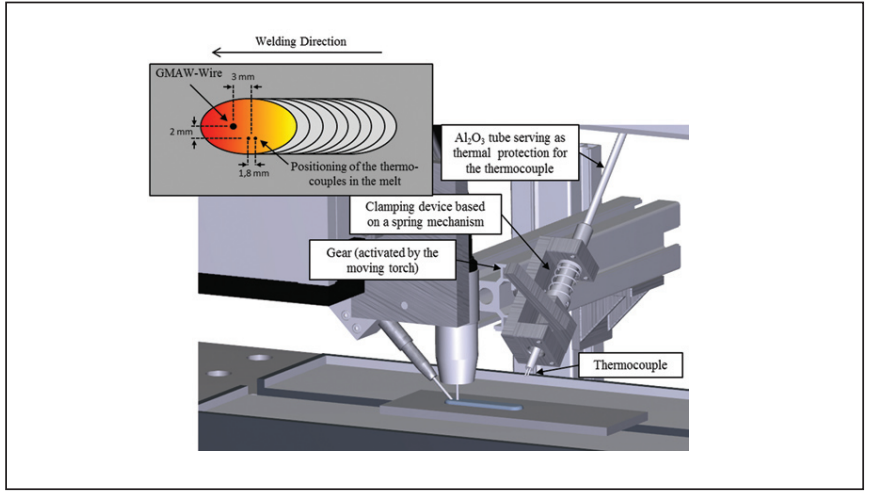

Fig. 2 - Experimental setup for temperature measurements by means of thermocouples (Type C).

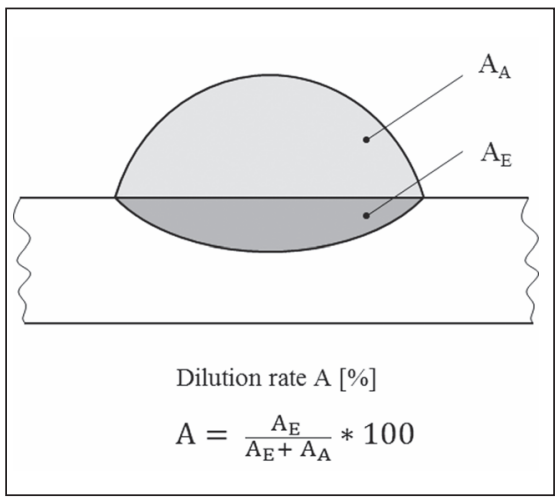

Fig. $3-$ Determination of the dilution rate $A$.

properties are known to have a negative impact on the degradation behavior of FTCs. One reason for this impact is the FTCs' direct exposure to the arc during the material transfer. A further challenge is the direct correlation between the material and energy input. Hence, increasing deposition rates are accompanied by a rising heat input into the melt, promoting high dilution rates and an elevated degradation of FTCs.

Vespa et al. (Ref. 15) and Badisch et al. (Ref. 8) determined that increasing wire feed speeds $v_{G M A W}$ and welding voltages $U_{G M A W}$ result in an increasing dilution and decreasing FTC content in the Ni-based alloy. Comparable results were described by Choi et al. (Ref. 9). Consequently, the productivity of GMAW as a deposition technique is limited, as welding with reduced energy input is recommended (Ref. 16).

To improve the productivity of GMAW, a separation of the material and energy input is required. The application of an additional hot wire (HWGMAW), which is directly fed in the melt pool, appears to be a promising

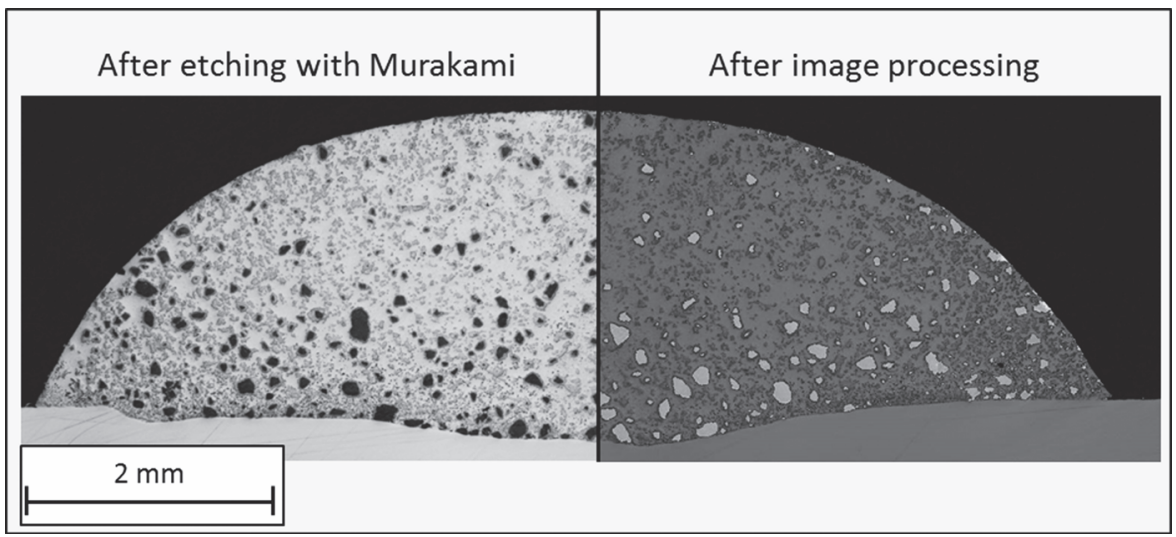

Fig. 4 - Cross section of a Ni-FTC weld joint after etching and after image processing. means of removing heat from the melt and avoiding thermal interactions between the arc and FTCs. Under these considerations, investigations were performed for GMAW and gas tungsten arc welding (GTAW). Gao et al. (Ref. 17) determined that hot wire-assisted GTAW leads to a reduced degradation of FTCs and results in a homogeneous distribution of the hard phases in the matrix materials compared to cold wire-assisted GTAW. Guest (Ref. 18) and Günther et al. (Ref. 16) found an additional hot wire also has a positive influence on GMA welded Ni-FTC hardfacing. The dilution rate is reduced, and the hard phase distribution is more homogenized compared to conventional GMAW. However, the observed deposition rates did not exceed $6 \mathrm{~kg} / \mathrm{h}$ and were hence clearly below typical PTAW deposition rates of approximately 12 $\mathrm{kg} / \mathrm{h}$. Furthermore, the reason for the decrease in the dilution rate and the homogeneous hard phase distribution has not been experimentally demonstrated to date. Under these considerations, experimental investigations were performed based on the following hypotheses:

- Applying an additional hot wire during GMAW leads to a decrease in the dilution rate as the maximum melt bead temperatures decrease.

- The partitioning of the material via both the consumable electrode and the hot wire enables a separate adjustment of the dilution and deposition rate.

- The insertion of FTCs via the hot wire counteracts a thermal exposure to
Table 1 - Chemical Composition of the Investigated Ni-FTC Flux Cored Wire

Composition of the Ni-FTC flux cored wire [wt-\%]

\begin{tabular}{ccccc}
$\mathrm{Ni}$ & $\mathrm{C}$ & $\mathrm{Si}$ & $\mathrm{B}$ & FTC \\
\hline Rest & 0.40 & 1.20 & 2.05 & 55.00 \\
\hline
\end{tabular}




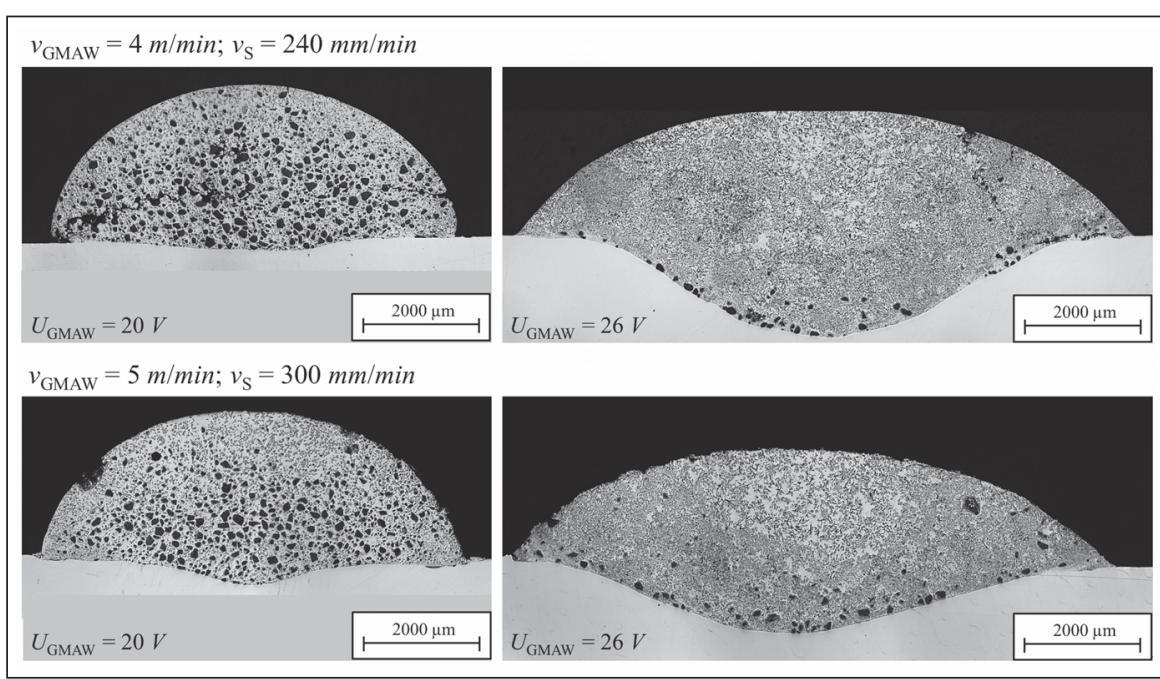

Fig. 5-Amount and distribution of FTCs (black colored) for different GMAW process parameters.

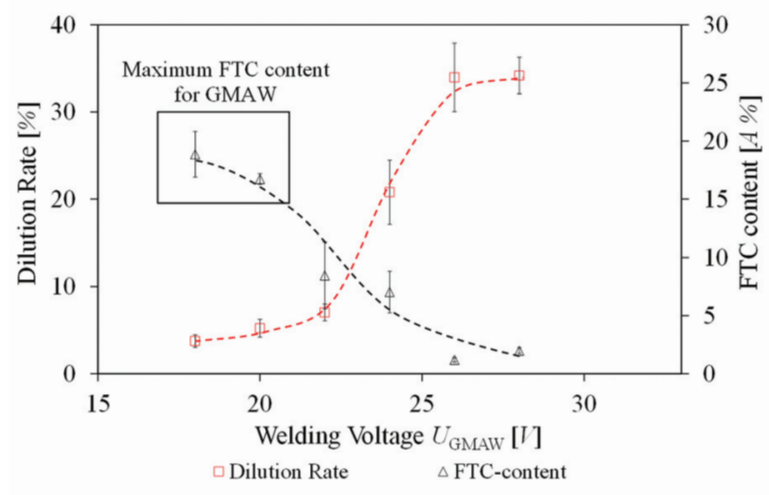

Fig. 6 - FTC content and dilution rate dependence on the welding voltage $\mathrm{U}_{\mathrm{GMAN}}$ $\left(\mathrm{v}_{\mathrm{GMAW}}=4 \mathrm{~m} / \mathrm{min}, \mathrm{v}_{\mathrm{s}}=240 \mathrm{~mm} / \mathrm{min}\right)$.

the arc and contributes to a reduced degradation of FTCs.

- The homogeneous distribution of the hard phases during hot wire assisted GMAW is the result of a modified melt bead flow compared to conventional GMAW.

\section{Materials and Methods}

\section{Equipment, Materials, and Methods}

The experiments were performed with an Alpha Q 552 GMAW power source. As a hot wire power supply, a Triton 260 TGD instrument was used for resistance heating. The maximum voltage was limited to $8 \mathrm{~V}$ to avoid a spontaneous arc ignition. The setup of the GMAW gun and HW nozzle is schematically illustrated in Fig. 1 . The movement was executed with a linear ISEL actuator.

A NiBSi flux cored wire (ø $1.2 \mathrm{~mm})$ with FTCs was applied for both the GMAW filler material and the external hot wire. The element composition is listed in Table 1 . Ar mixed with $2 \%$ $\mathrm{CO}_{2}$ served as the protective gas.

Unalloyed steel S355 J2+N $(5 \times 50 \times$ $150 \mathrm{~mm}$ ) was used as the substrate material for a defined weld joint length of $120 \mathrm{~mm}$. Before the welding tests, the substrate surface was degreased with isopropanol and then fixed on a watercooled clamping tool to ensure reproducible testing conditions.

\section{Electrical Process Parameters}

The welding current $I_{G M A W}$, welding voltage $U_{G M A W}$, hot wire current $I_{H W}$, and hot wire voltage $U_{H W}$ were detected using a digital oscilloscope (Dewe 800) at a frequency of $50 \mathrm{kHz}$. These values were used to calculate the process powers $P_{G M A W}$ and $P_{H W}$, as well as the total process power $P_{G M A W+H W}$, according to Equations 2 and 3 .

$$
\begin{gathered}
\overline{P_{G M A W+H W}}=\overline{I_{G M A W} U_{G M A W}}+\overline{I_{H W} U_{H W}} \\
\overline{P_{G M A W+H W}}=\overline{P_{G M A W}+P_{H W}}
\end{gathered}
$$

Additionally, $U-I$ measurements were performed to ensure a continuous feeding of the hot wire in the melt pool. A premature dripping of the hot wire tip before entering the melt pool was indicated by interruptions of the current profile and could thus be avoided. The hot wire current $I_{H W}$ was always adjusted according to the wire feed speed $v_{H W}$ to ensure the welding wire remain in contact with the melt.

\section{Temperature Measurements and IR Imaging}

The influence of an additional hot wire on the GMAW melt bead temperature was determined via thermocouples of Type C (Pt-5\%Re/Pt-26\%Re), which were inserted in the melt pool according to Fig. 2. The feeding of the thermocouples was realized by a spring mechanism, which was mechanically activated by the moving gun. Infrared images (ImageIR ${ }^{\circledR} 8300$ ) of the melt pool finally provided information concerning the melt bead flow and its influence on the hard phase distribution.

\section{Metallographic Investigations}

For metallographical investigations, three cross sections were extracted per sample at weld joint lengths of 40,50 , and $60 \mathrm{~mm}$, and were subsequently metallographically prepared in a multistage procedure. Macroscopically, the cross sections were evaluated with respect to the dilution rate - Fig. 3. Additionally, cross sections were etched with Murakami regency, leading to a black coloring of FTCs in the Ni-based alloy. Automatic determination of the FTC content in the Ni-based alloy was enabled. A Matlab-based image processing tool was used to detect the FTC content [in area percent $(\mathrm{A} \%)$ ] automatically. The resolution of the images was 2.7 pixels $/ \mu \mathrm{m}-$ Fig. 4 . 


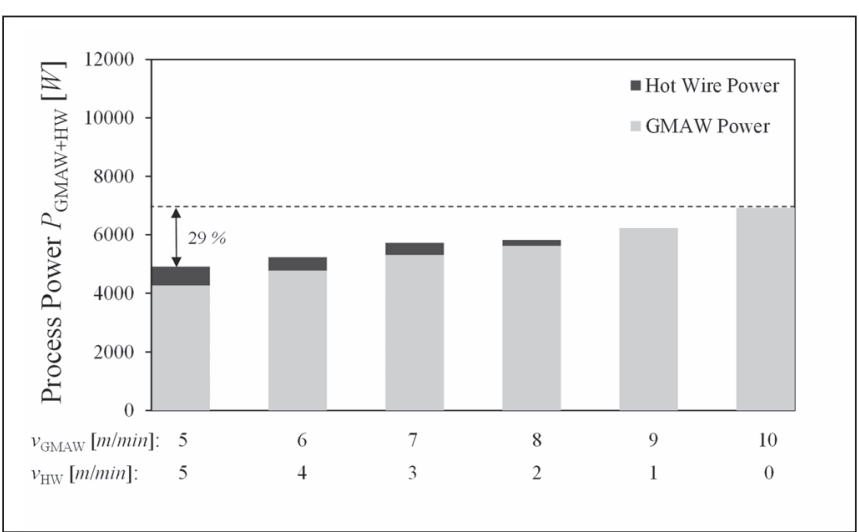

Fig. 7 - Influence of the wire feed ratio $\mathrm{v}_{\mathrm{GMAW}} / \mathrm{V}_{\mathrm{HW}}$ on the process powers $\mathrm{P}_{\mathrm{GMAW}+\mathrm{HW}}$ for a total wire feed speed $\mathrm{V}_{\mathrm{GMAW}+\mathrm{HW}}$ of $10 \mathrm{~m} / \mathrm{min}$.

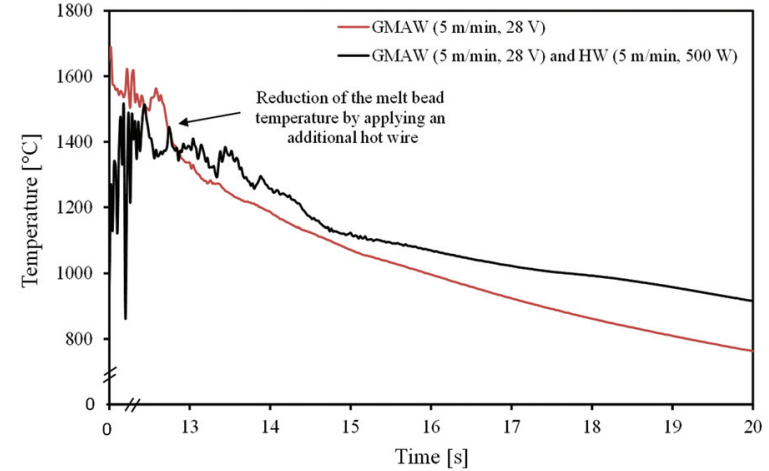

Fig. 8 - Reduction of the melt bead temperature by applying an additional hot wire during GMAW surfacing.

\section{Wear Testing}

To compare the wear resistance between GMAW and HW-GMAW hardfacings, a two-body abrasive wear test ("Verschleißtopftest") was performed (Ref. 19). Three specimens $(15 \times 15 \times$ $25 \mathrm{~mm}$ ) were extracted out of each planar overlay weld and fixed in a rotating stamp. The specimens underwent a 12-h lasting test in a counterrotating container filled with washed silicon oxide crystals ( $\varnothing 4$ to $6 \mathrm{~mm}$ ) as an abrasive. The abrasive speed was 2.9 to $3.2 \mathrm{~m} / \mathrm{s}$ based on a spindle speed of $850 \mathrm{rpm}$ and a container rotating speed of $10 \mathrm{rpm}$. By measuring the mass loss and the gravimetric density of the hardfacing, the specific volumetric wear resistance $1 / W_{V R 12}$ was determined in relation to unalloyed steel S235 JR+N.

\section{Scope of Testing}

To characterize the influence of an additional hot wire reliably, comparative examinations were performed between GMAW and HW-GMAW.

Regarding GMAW, wire feed speeds $v_{\text {GMAW }}$ of 4 and $5 \mathrm{~m} / \mathrm{min}$ were taken into consideration. The observed welding voltages $U_{\text {GMAW }}$ varied between 18 and $30 \mathrm{~V}$.

Regarding HW-GMAW, the material transfer was split on both the consumable GMAW electrode and the hot wire. The sum of the wire feed speeds $v_{G M A W+H W}$ was up to $20 \mathrm{~m} / \mathrm{min}$. In the case of HW-GMAW, the consumable electrode was performed with relatively high voltages (Table 2). The ob-

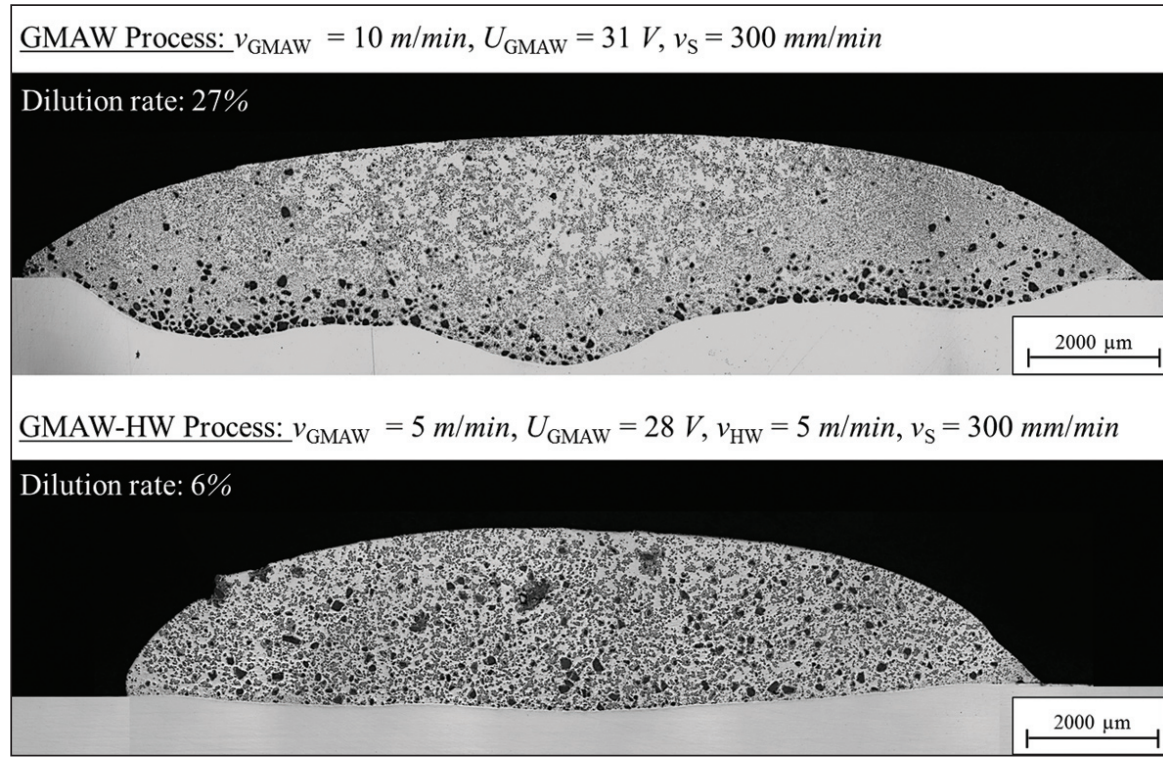

Fig. 9 - Comparison between GMAW and HW-GMAW of the achieved dilution rate A for a total wire feed speed of $10 \mathrm{~m} / \mathrm{min}$.

Table 2 - Welding Parameters for Consumable Electrode during Hot Wire-Assisted Gas Metal Arc Welding (HW-GMAW)

GMAW wire feed speed $v_{\text {GMAW }}[\mathrm{m} / \mathrm{min}]$

\begin{tabular}{ccccccc} 
& 5 & 6 & 7 & 8 & 9 & 10 \\
\hline $\mathrm{U}_{\text {GMAN }}[\mathrm{V}]$ & 28 & 28.5 & 29 & 29.5 & 30 & 31 \\
\hline
\end{tabular}

jective was to ensure an adequate melt bead temperature and size to provide a reliable melting of the hot wire when entering the melt bead. These GMAW process parameters were determined by means of pretests. As previously mentioned, the hot wire current $I_{H W}$ was adjusted according to the wire feed speed $v_{H W}$ to ensure continuous feeding conditions.

\section{Results}

\section{GMAW of FTC-Reinforced Ni-Based Hardfacing}

To evaluate the impact of an additional hot wire on the macro- and microscopic features, comparative examinations were first performed for conventional GMAW. The macro- and mi- 


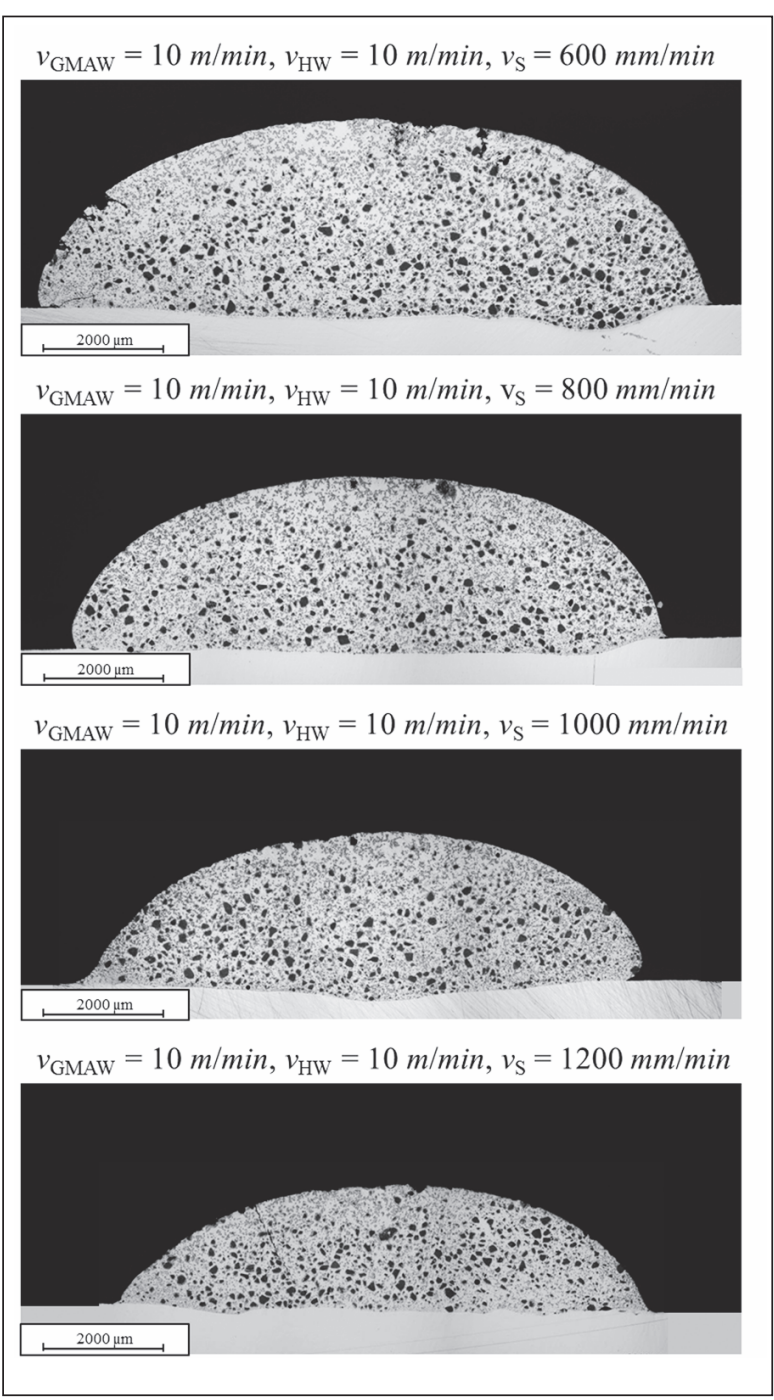

Fig. 10 - Influence of the welding speed $\mathrm{v}_{\mathrm{s}}$ on the dilution rate at a deposition rate of $11.8 \mathrm{~kg} / \mathrm{h}$ and a wire feed ratio $\mathrm{v}_{\mathrm{GMAW}} / \mathrm{v}_{\mathrm{HW}}=1$.
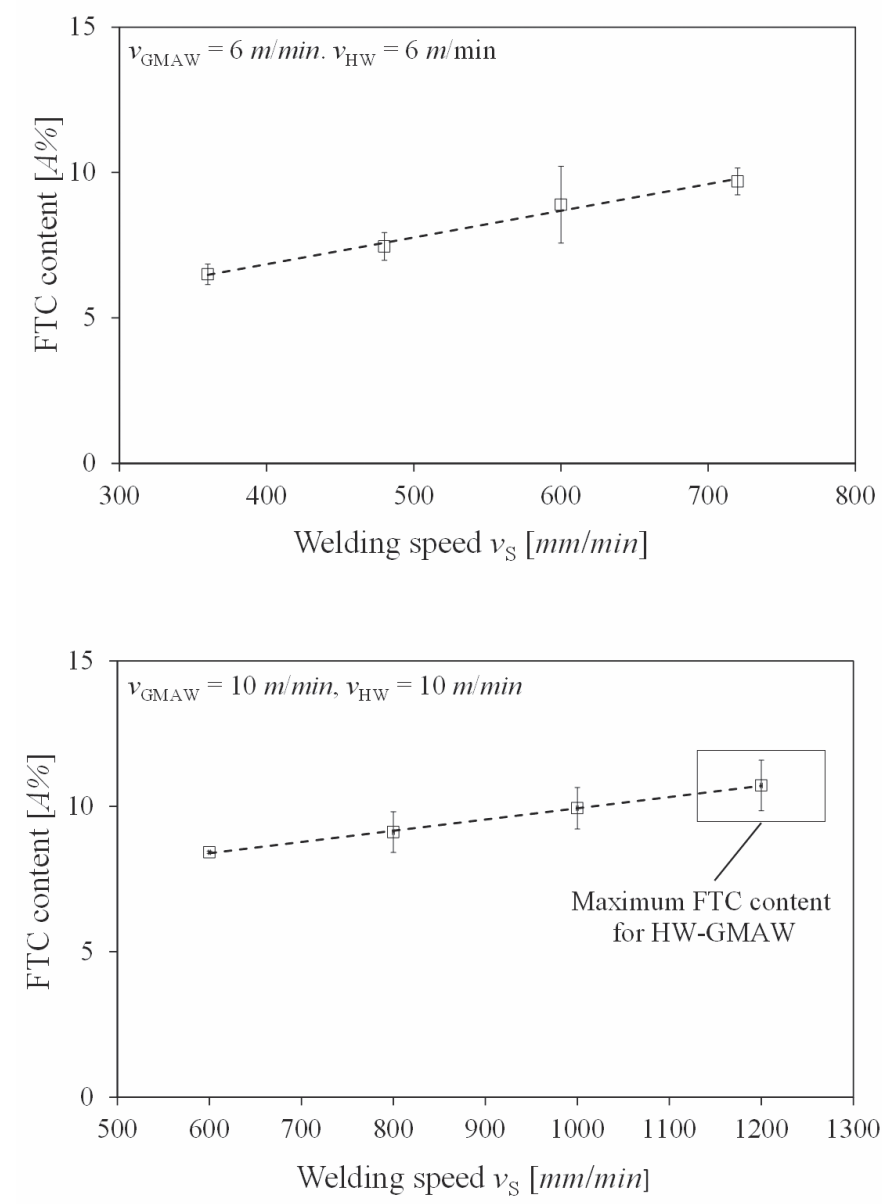

Fig. 11 - Influence of the HW-GMAW process parameters on the FTC content for a wire feed ratio $\mathrm{v}_{\mathrm{GMAW}} / \mathrm{v}_{\mathrm{HW}}$ of $\mathrm{l}$. crostructural appearance of $\mathrm{Ni}$-based hardfacings is shown in Fig. 5. Briefly, two different effects are apparent. Because of the differences in density between the hard phases and the Nibased alloy, FTCs tend to segregate in the matrix material. Furthermore, the dilution rate and dissolution of FTCs are considerably influenced by the GMAW process parameters.

The increase of the wire feed speed $v_{\text {GMAW }}$ from 4 to $5 \mathrm{~m} / \mathrm{min}$ (at constant welding voltage $U_{G M A W}$ ) leads to an increase in the dilution rate and decrease in the FTC-content - Fig. 5. This effect shows the increase in the welding current $I_{G M A W}$ has a larger effect than the increase in the material deposited, thereby effectively decreasing the overall heat per unit mass that has the opposite effect. Furthermore, the increase in welding voltage $U_{\text {GMAW }}$ (at constant $v_{\text {GMAW }}$ ) leads to an increase in the dilution rate and a decrease in the FTC content - Fig. 5.

Figure 6 presents details of this observation for a wire feed speed $v_{\text {GMAW }}$ of $4 \mathrm{~m} / \mathrm{min}$. The maximum amount of FTCs ( 20 A\%) in the Ni-based alloy is restricted to the lowest heat input, represented by a wire feed speed $v_{G M A W}$ of $4 \mathrm{~m} / \mathrm{min}$ and a welding voltage $U_{G M A W}$ of 18 to $20 \mathrm{~V}$ - Fig. 6 . The increase in $U_{\text {GMAW }}$ directly leads to a distinctive decrease in the FTC content down to minimum values of $2 \mathrm{~A} \%$.

Although the primary effects for the decrease in the FTC content will be discussed later, the results demonstrate that the amount of FTCs is re- stricted by the deposition rate and hence the energy input. These findings demonstrate the necessity of decoupling the material and heat input by means of an additional hot wire during GMAW.

\section{Influence of an Additional Hot Wire on the Dilution and FTC Content}

To understand the influence of an additional hot wire on the heat input, the impact on the process power $\mathrm{P}$ was examined first. A GMAW process with a wire feed speed $v_{G M A W}$ of $10 \mathrm{~m} / \mathrm{min}$ and a process power $P_{G M A W}$ of $\sim 7 \mathrm{~kW}$ served as reference - Fig. 7. By steadily replacing the material input with a hot wire, 
$P_{\text {GMAW }+H W}$ can be reduced from $\sim 7$ to $\sim 5$ $\mathrm{kW}$, equivalent to a decrease of $29 \%$. This effect can be attributed to the low hot wire power $P_{H W}$ necessary to melt the welding wire. The maximum $P_{H W}$ is $\sim 650 \mathrm{~W}, 15 \%$ of $P_{G M A W}$ for wire feed speeds of $5 \mathrm{~m} / \mathrm{min}$.

Additionally, Fig. 8 illustrates that the application of an additional hot wire has a direct impact on the melt bead temperatures. The maximum melt bead temperatures of the GMAW process were reduced from $\sim 1550^{\circ}$ to $\sim 1400^{\circ} \mathrm{C}$, whereas the material input doubled from 5 (GMAW) to $10 \mathrm{~m} / \mathrm{min}$ (HW-GMAW). This finding demonstrates the effectiveness of the approach to separate the energy and material input by means of an additional hot wire.

The influence on the melt bead temperatures had an immediate impact on the heat input and dilution rate of the hardfacing. Figure 9 shows comparative cross sections between a GMAW $\left(v_{\text {GMAW }}=10 \mathrm{~m} / \mathrm{min}\right)$ and a HWGMAW hardfacing $\left(v_{G M A W}=5 \mathrm{~m} / \mathrm{min}\right.$, $v_{H W}=5 \mathrm{~m} / \mathrm{min}$ ). Despite a comparable deposition rate of $\sim 6 \mathrm{~kg} / \mathrm{h}$, the dilution rate A could be reduced from $\sim 27$ to $\sim 8 \%$ by applying a hot wire.

Further investigations were performed with varying welding speed $v_{S}$ (300-1200 $\mathrm{mm} / \mathrm{min}$ ) as well as wire feed speeds $v_{G M A W}$ and $v_{H W}(5-10 \mathrm{~m} /$ $\min )$. Based on a wire feed ratio of 1 , comparable effects are visible for deposition rates of up to $\sim 11.8 \mathrm{~kg} / \mathrm{h}$ $\left(v_{\text {GMAW }}=10 \mathrm{~m} / \mathrm{min}, v_{H W}=10 \mathrm{~m} / \mathrm{min}\right)$, whereby the dilution rate consistently varied between 3 and $8 \%$ - Fig. 10. Furthermore, it is clear that the welding speed $v_{S}$ does not significantly influence the dilution in the parameter ranges tested. Furthermore, the cross sections show the application of the hot wire leads to a homogeneous distribution of FTCs.

The influence of the process parameters on the FTC content is representatively shown in Fig. 11. An increase of the welding speed $v_{S}$ and wire feed rates $v_{G M A W}$ and $v_{H W}$ directly goes along with the percentage increase of the amount of FTC in the matrix. Maximum values of $11 \mathrm{~A} \%$ were achieved for welding speeds $v_{S}$ above 1000 $\mathrm{mm} / \mathrm{min}$ and a deposition rate of approximately $11.8 \mathrm{~kg} / \mathrm{h}\left(v_{\text {GMAW }}=10\right.$ $\left.\mathrm{m} / \mathrm{min}, \mathrm{v}_{\mathrm{HW}}=10 \mathrm{~m} / \mathrm{min}\right)$. Nevertheless, the maximum achieved FTC con-

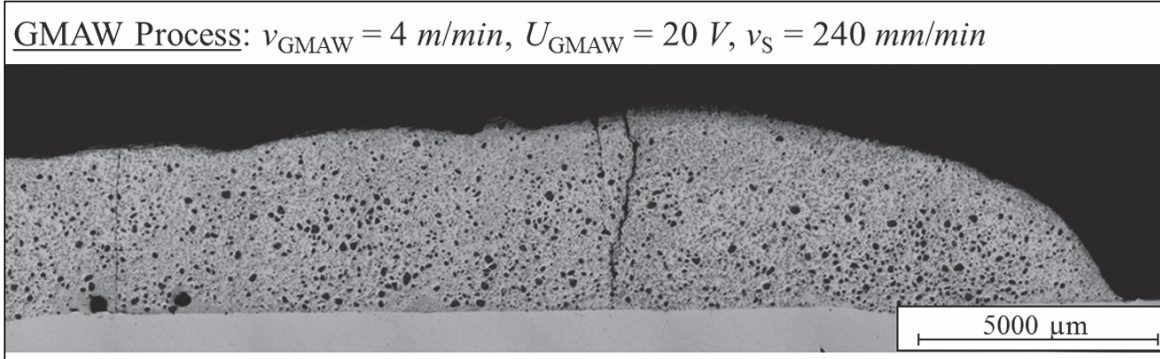

GMAW-HW Process: $v_{\mathrm{GMAW}}=10 \mathrm{~m} / \mathrm{min}, v_{\mathrm{HW}}=10 \mathrm{~m} / \mathrm{min}, v_{\mathrm{S}}=1000 \mathrm{~mm} / \mathrm{min}$

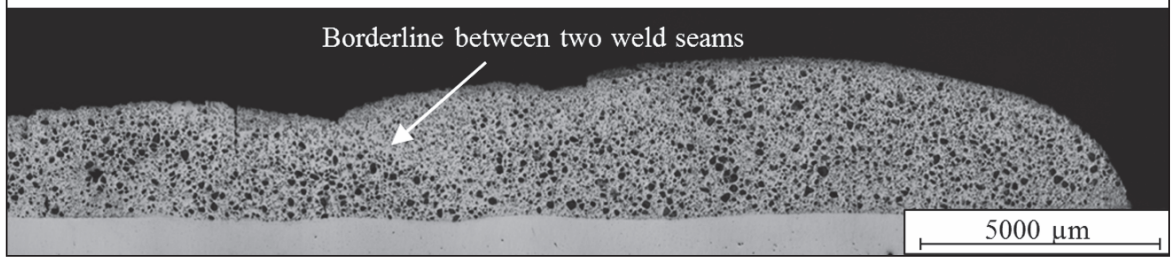

Fig. 12 - Cross sections of single-layer GMAW and HW-GMAW hardfacing.

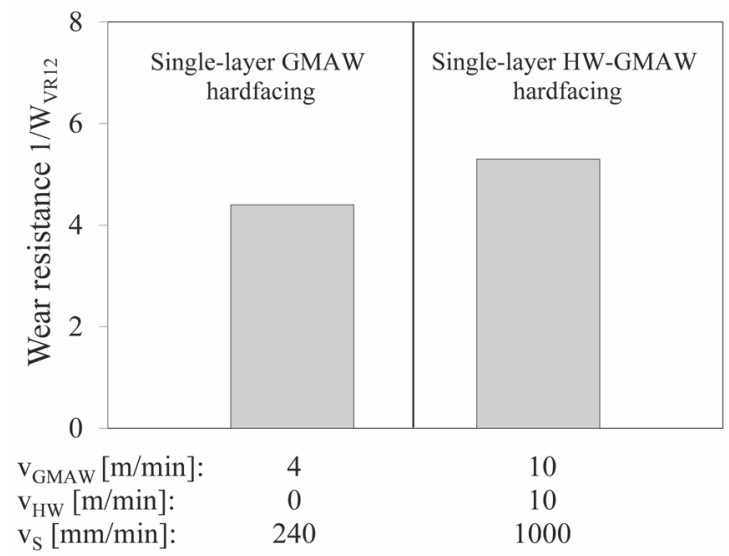

Fig. 13 - Wear resistance of single-layer GMAW and HW-GMAW hardfacing.

tent is half of the optimum GMAW process window.

\section{Planar Overlay Welds and Wear Testing}

To transfer the obtained results to practical applications, an immediate comparison between the planar GMAW and the HW-GMAW hardfacings was performed. HW-GMAW surfacings were conducted with wire feed speeds $v_{G M A W}$ and $v_{H W}$ of $10 \mathrm{~m} / \mathrm{min}$ and a welding speed $v_{S}$ of $1000 \mathrm{~mm} / \mathrm{min}$ because this parameter setup was demonstrated to be favorable with respect to the FTC content (compare Fig. 11). Regarding GMAW, the hardfacings were performed with the optimum parameter $\operatorname{setup}\left(v_{\text {GMAW }}=4 \mathrm{~m} / \mathrm{min}, U_{\text {GMAW }}=20 \mathrm{~V}, v_{S}\right.$ $=240 \mathrm{~mm} / \mathrm{min}$ ). In both cases, a dilution rate of $\sim 5 \%$ was achieved, whereby the deposition rate of the HW-GMAW process was five times higher - Fig. 12.

The determined FTC content of the HW-GMAW hardfacing amounts to approximately $11.5 \mathrm{~A} \%$ and is comparable to the above-described investigations concerning single overlay welds. Instead, GMAW overlays exhibited a percentage amount of $7.5 \mathrm{~A} \%$, which is clearly below the value of single-layer welds ( $20 \mathrm{~A} \%)$. The reason for this effect will be discussed later. This result was also reflected by the wear resistance $1 / \mathrm{W}_{\mathrm{VR} 12}$. For HW-GMAW, a value $1 / W_{V R 12}$ of 5.3 was achieved. In case of GMAW, the surfacing showed a lower wear resistance of 4.4 - Fig. 13. 


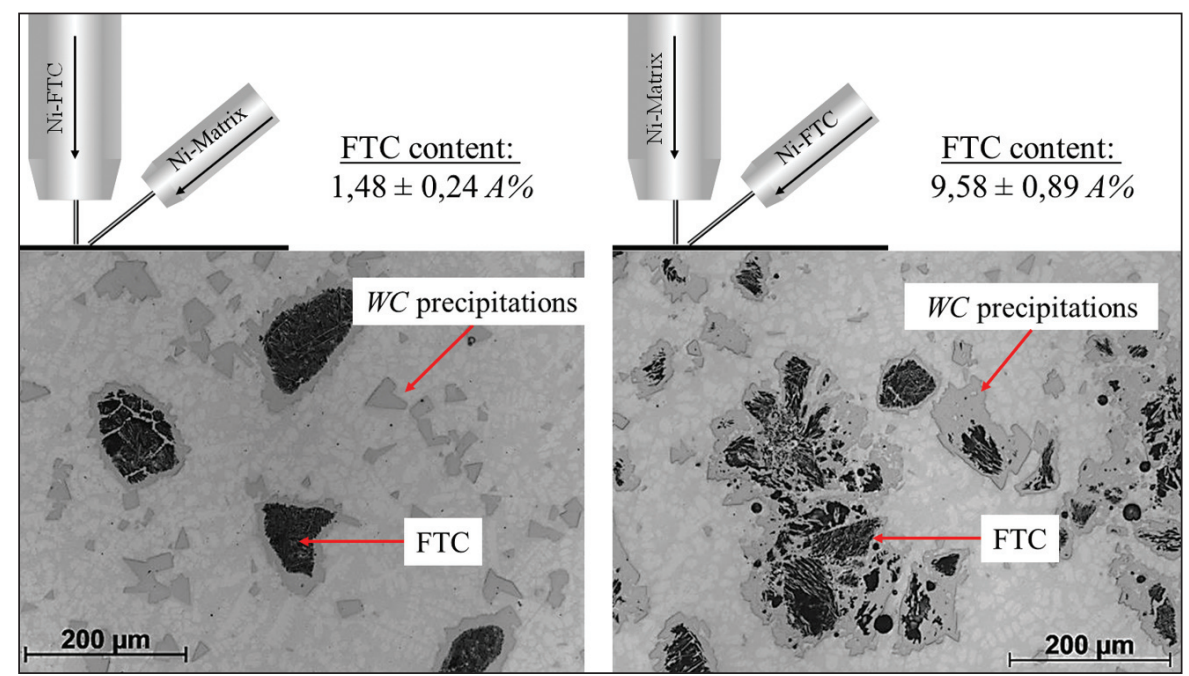

Fig. 14 - Influence of the FTC feeding conditions on the FTC content (process parameters: $\mathrm{v}_{\mathrm{GMAW}}=5 \mathrm{~m} / \mathrm{min}, \mathrm{v}_{\mathrm{HW}}=5 \mathrm{~m} / \mathrm{min}, \mathrm{v}_{\mathrm{S}}=300 \mathrm{~mm} / \mathrm{min}$ ).

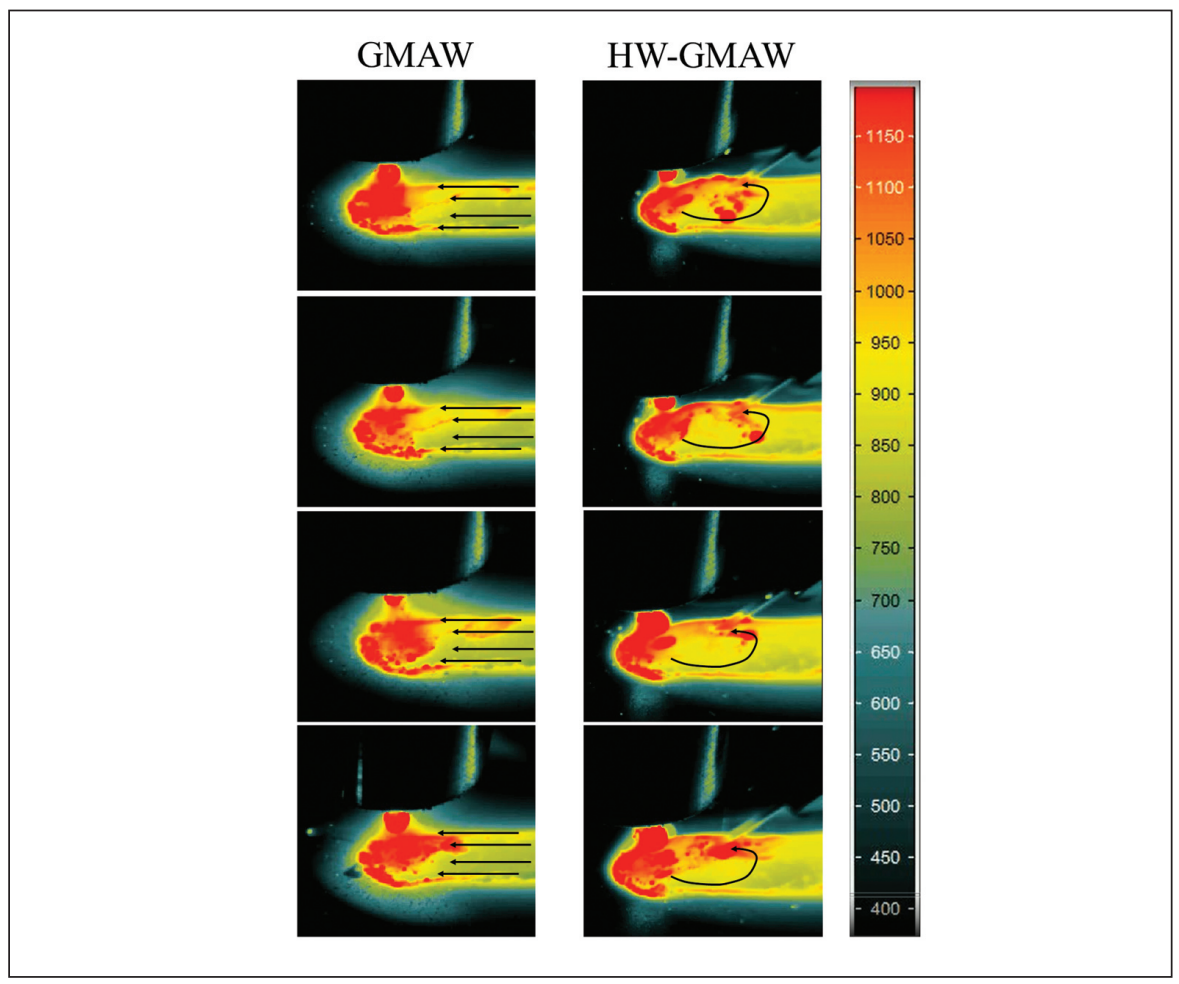

Fig. 15 - Modification of the melt flow due to an additional hot-wire application.

\section{Discussion}

\section{Parameters Affecting the Degradation of FTCs}

The results described show that the maximum achieved FTC content during GMAW surfacing is restricted to a narrow process window based on a low heat input in short arc mode $\left(v_{G M A W}=4\right.$ $\left.\mathrm{m} / \mathrm{min}, U_{G M A W}=18-20 \mathrm{~V}\right)$, compare
Fig. 6. As a consequence, low deposition rates achieved by applying a short circuit transfer are required to obtain highly wear resistant hardfacings, thereby limiting the productivity of the surfacing process. The abovedescribed results reveal a quantitative correlation between the loss of FTCs and the dilution - Fig. 6.

In this context, one reason for FTC losses is the degradation promoting influence of the dilution, as discussed by Badisch et al. (Ref. 8), Choi et al. (Ref. 9), and Günther et al. (Ref. 7), who referred to the formation of $\mathrm{W}$ and Fe-rich precipitates in the matrix material. However, the increase in the dilution rate is not the only FTC loss mechanism during GMAW. Guest et al (Ref. 20) discovered FTCs may not be inserted in the melt pool, as they bounce off the melt pool surface; he called this process the nonwetting effect. Günther et al. (Ref. 7) found overspray has a significant influence on FTC losses during GMAW. Furthermore, the increase in the welding voltage $U_{G M A W}$ from 18 to $28 \mathrm{~V}$ (Fig. 6) impacts the droplet transfer from short circuit mode to globular transfer (> 28 $\mathrm{V})$. Clearly, a change in the droplet transfer influences the FTC dissolution, whereby Ni-FTC hardfacings manufactured in globular transfer show advanced degradation compared to short circuit mode (Ref. 9).

In this context, it must be assumed the direct interaction between the arc and FTCs influences the degradation behavior significantly. This effect is supported by Siewert (Ref. 21), who found the melt bead temperature is $\sim 1000^{\circ} \mathrm{C}$ lower compared to the material transfer in the arc. From this point of view, the application of an additional hot wire is a promising approach to decouple the energy and material transfer and to control the melt bead temperature independently of the deposition rate. As a result, low-dilution claddings (with a dilution rate of $~ 5 \%$ ) were enabled for deposition rates of up to $11.8 \mathrm{~kg} / \mathrm{h}$ by applying a wire feed ratio $v_{G M A W} / v_{H W}$ of 1 - Fig. 10 .

However, HW-GMAW reaches only half of the maximum FTC content ( 20 A\%), which was achieved within the optimized process window of GMAW $\left(v_{G M A W}=4 \mathrm{~m} / \mathrm{min}, U_{G M A W}=18\right.$ $\mathrm{V})$. As HW-GMAW overlays show comparable dilution rates of 3 to $8 \mathrm{~A} \%$, the influence of these low dilution rates on the FTC degradation is considered to be negligible (Ref. 7). Hence, the cause for the reduced FTC content in the case of HW-GMAW must lie in the thermal degradation of FTCs during the material transfer in the arc.

A quantification of the degradation behavior of FTCs during the droplet transfer has not been performed to date. To support the above-mentioned assumption, the FTC content achieved 
with the consumable GMAW electrode and the hot wire was observed separately - Fig. 14. The supply of FTCs via the hot wire was accompanied by the use of a pure NiBSi matrix alloy as a consumable GMAW electrode and vice versa. The pure NiBSi matrix alloy had a comparable chemical composition, as listed in Table 1 but without FTCs.

According to Fig. 14, the percentage amount of FTCs inserted via the hot wire amounts to $~ 9 \mathrm{~A} \%$ and is 5 to 6 times higher compared to the arcassisted supply via the consumable GMAW electrode. For comparison, the amount of FTCs inserted via the arc electrode amounts to $1.5 \mathrm{~A} \%$. Instead, FTCs inserted via the hot wire undergo a lower thermal impact as they are not directly exposed to the high arc temperatures. Consequently, the comparatively low FTC content of HW-GMAW hardfacings can primarily be attributed to the thermally induced degradation of FTCs in the arc.

\section{Influencing the Distribution of the Hard Phases in the Melt}

The segregation of FTCs in Nibased hardfacings during GMAW is a well-known effect that can be avoided by applying an additional hot wire. Günther et al. (Ref. 16) assumed the homogeneous hard phase distribution resulted from the fact the FTCs are directly fed in the back part of the solidifying melt pool. Thus, FTCs are not given the necessary time to segregate. A comparable effect was observed by Gao et al. (Ref. 17) during hot wireassisted gas tungsten arc welding (GTAW), which referred to the reduced melt bead dimensions and bead size.

The above-explained effects, however, have not yet been proven. To determine the reason for the homogeneous hard phase distribution, the insertion of FTCs via the consumable GMAW electrode and the hot wire were observed separately.

In contrast to conventional GMAW, the hot wire causes a rather circular melt flow characteristic, promoting conditions for a homogeneous mixing of the melt - Fig. 15. However, metallographic examinations showed the segregation of FTCs is not prevented, whereby FTCs inserted either via the hot wire or the GMAW consumable electrode are not homogeneously dis-
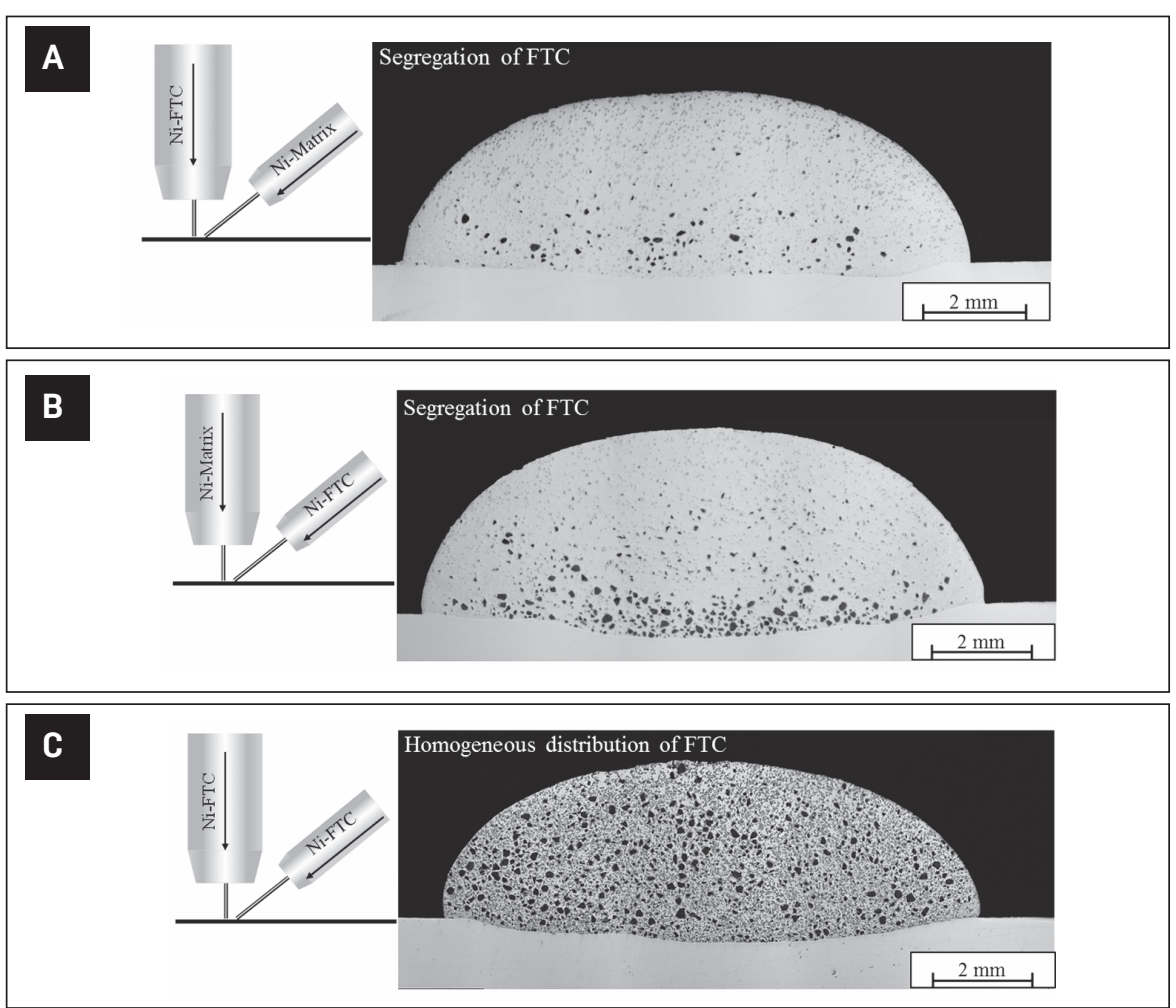

Fig. 16 - Influence of the FTC feeding condition on the distribution of FTCs in the matrix material $\left(\mathrm{V}_{\mathrm{GMAW}}=8 \mathrm{~m} / \mathrm{min}, \mathrm{v}_{\mathrm{HW}}=8 \mathrm{~m} / \mathrm{min}, \mathrm{v}_{\mathrm{S}}=520 \mathrm{~mm} / \mathrm{min}\right)$.

tributed in the matrix - Fig. 16A, B. Apparently, there is still sufficient time for the hard phases to segregate. The modified melt flow conditions only lead to a homogeneous distribution, unless FTCs are inserted via both the consumable electrode and the hot wire (Fig. 16C) and promote the adjustment of a critical hard phase content. Hence, the homogeneous distribution of FTCs in the matrix is based on two conditions: a modified melt flow, which promotes a homogeneous mixing of the melt, and a hard phase content, which is sufficiently high to serve as a barrier against subsequent segregation.

\section{Planar Hardfacings}

The investigations of planar hardfacings (Fig. 12) revealed the thermal impact on FTCs of already deposited weld joints must also be considered. Although the GMAW process window shows the highest amount of FTCs ( 20 A\%) with respect to single weld joints, the FTC content of planar hardfacings is rather low ( 7.5 A\%). This effect is due to the remelting of the deposited weld joints, promoting the degradation of FTCs in the already solidified weld joints. In contrast, a comparable effect during HWGMAW is not visible, as indicated by the clear boundary between the layers, demonstrating no remelting of the adjacent layers due to a reduced heat input.

Consequently, the FTC content ( $11.5 \mathrm{~A} \%)$ was comparable to the above-obtained results concerning single-layer welds. As a result, the wear resistance of HW-GMAW hardfacing is higher compared to conventional GMAW (see Fig. 13). Hence, planar surfacing reveals HW-GMAW is a process strategy that improves both productivity and exploitation of Ni-based hardfacings with embedded FTCs.

\section{Summary and Outlook}

The application of an additional hot wire improved the process characteristics of GMAW via deposition-independent control of the maximum melt bead temperature. Consequently, the separation of the energy and material input enabled an independent adjustment of the deposition and dilution rate. As a result, overlay welds with di- 
lution rates of $\sim 5 \%$ and deposition rates of up to $\sim 12 \mathrm{~kg} / \mathrm{h}$ can be realized, approaching the PTAW standards.

The application of an additional hot wire influenced the characteristic of FTC considerably. First, a modified melt bead flow avoided typical segregation effects and contributed to a homogeneous distribution of FTCs in the melt. Second, planar HW-GMAW overlays exceeded the FTC content and wear resistance compared to conventional GMAW. The reason for this phenomenon is the low thermal impact of HW-GMAW, counteracting a remelting of the already deposited layers, thereby reducing the thermal impact of FTCs embedded in the deposited layers considerably.

The following recommendations should be considered for HW-GMAW to obtain a maximum amount of FTC: - Welding speeds $v_{S} \geq 1000 \mathrm{~mm} / \mathrm{min}$ - Deposition rates $v_{G M A W}, v_{H W} \geq 8 \mathrm{~m} / \mathrm{min}$.

Based on these findings, subsequent investigations will pursue welding wire diameters of up to $2.4 \mathrm{~mm}$ to further increase the content and size of FTC positively. In this context, the independent change of the characteristics of the wires, such as placing a higher FTC fraction wire as the hot wire and a lower fraction as the consumable electrode, should be considered to further improve the process.

\section{Acknowledgments}

This research project (IGF-Number 18.008 BR/DVS-Nr. 03.119) was supervised by the German Research Association on Welding and Allied Processes (DVS) and sponsored by the German Ministry of Economy and Energy. The authors would like to thank these organizations for their support. The authors particularly thank EWM $\mathrm{AG}$ and Corodur Fülldraht $\mathrm{GmbH}$ for providing support with the necessary equipment and materials.

\section{References}

1. Amado, J. M., Tobar, M. J., Alvarez, J. C., Lamas, J., and Yanez, A. 2009. Laser cladding of tungsten carbides (Spherotene) hardfacing alloys for the mining and mineral industry. Applied Surface Science 255: 5553-5556. DOI: https://doi.org/10.1016/ j.apsusc.2008.07.198

2. Ottonello, G. B. 2007. Tungsten car- bides and welding. Welding International 21: 569-583. DOI: https://doi.org/ 10.1080/09507110701637874

3. Schreiber, F. 2000. WolframSchmelzkarbid im Verschleißschutz: Besonderheiten bei der schweißtechnischen Verarbeitung und Qualitätsicherung (Fused tungsten carbides: Particularities during welding processing). Scientific Article of Durum Verschleißschutz GmbH.

4. Berns, H. 1998. Hartlegierungen und Hartverbundwerkstoffe (Hardfacing alloys and metal-matrix-composites). Berlin, Germany. Springer.

5. Kublii, V. Z., and Velikanova, T. Y. 2004. Ordering in the carbide $\mathrm{W}_{2} \mathrm{C}$ and phase equilibria in the tungsten-carbon system in the region of its existence. Powder Metallurgy and Metal Ceramics 43: 630-644. DOI: 10.1007/s11106-0050032-3)

6. Kurlov, A. S., and Gusev, A. I. 2006. Tungsten carbides and W-C phase diagram. Inorganic Materials 42: 121-127.

7. Günther, K., Liefeith, J., Henckell, P., Ali, Y., and Bergmann, J. P. 2018. Influence of processing conditions on the degradation kinetics of fused tungsten carbides in hardfacing. International Journal of Refractory Metals \& Hard Materials 70: 224-231. DOI: https://doi.org/10.1016/j.ijrmhm. 2017.10.015

8. Badisch, E., and Kirchgassner, M. 2008. Influence of welding parameters on microstructure and wear behaviour of a typical NiCrBSi hardfacing alloy reinforced with tungsten carbide. Surface and Coatings Technology 202: 6016-6022. DOI: https://doi.org/10.1016/j.surfcoat.2008.0 6.185

9. Choi, L., Wolfe, M., Yarmurch, M., and Gerlich, A. 2011. Effect of welding parameters on tungsten carbide-metal matrix composites produced by GMAW. Proc. of Canadian Welding Association Conference, Alberta, Canada.

10. Klimpel, A., Dobrzanski, L., Lisiecki, A., and Janicki, D. 2005. The study of properties in Ni-WC wires surfaced deposits. Journal of Materials Processing Technology 164-165: 1046-1055. DOI: https://doi.org/10.1016/j.jmatprotec. 2005.02.195

11. Wolfe, T. B. B. 2010. Homogeneity of metal matrix composites deposited by plasma transferred arc welding. PhD dissertation. Alberta, Canada, University of Alberta.

12. Bock, A. 2005. Untersuchungen zum Plasma-Pulver-Auftragschweißen zur Verarbeitung von Ni-Basislegierungen zum Korrosions- und Verschleißschutz (Investigations on PTA surfacing of Ni-base alloys for corrosion and wear protection applications). $\mathrm{PhD}$ dissertation, Clausthal, Germany, Technical University of Clausthal.

13. Schnick, T., Schreiber, F., and Wenz,
T. 2005. Verschleißschutz durch Fülldrahtund Plasma-Pulver-Auftragschweißen (Wear protection by means of FCAW and PTA hardfacing). Proceedings of the $8^{\text {th }}$ Material Scientific Colloquium in Chemnitz, Germany.

14. Fahrenwald, H. J. 2003. Praxiswissen Schweißtechnik (Practical knowledge on welding). Werkstoffe, Prozesse, Fertigung, Wiesbaden, Germany, Vieweg und Teubner.

15. Vespa, P., Pinard P. T., Gauvin R., and Brochu M. 2012. Analysis of WC/Nibased coatings deposited by controlled short-circuit MIG welding. Journal of Materials Engineering and Performance 21: 865-876. DOI: https://doi.org/10.1007/ s11665-011-9947-7

16. Günther, K., Schulze, R., and Bergmann, J. P. 2013. Hot wire assisted gas metal arc welding of Ni-FTC hardfacings. Welding and Cutting 12: 382-387.

17. Gao, S., Nakashin, H., Yamamoto M., Shinozaki, K., Kadoi, K., Watanabe, H., Kanazawa, T., and Gerlich, A. P. 2013. Development of WC hardfacing welding process using pulse heated hot-wire gas tungsten arc welding system. Quarterly Journal of Japan Welding Society 31: 57-60. DOI: https://doi.org/10.2207/qjjws. 31.57s

18. Guest, S. D. 2014. Depositing NiWC wear resistant overlays with hot-wire assist technology. PhD dissertation. Alberta, Canada, University of Alberta.

19. N. N., VDI-Richtlinie 4473. 2017. Abrasionsverschleißprüfstand für Komponenten von Schüttgutförderanlagen - Verschleißtopfverfahren (Entwurf) (Abrasive wear test for components of bulk material conveying systems - draft).

20. Guest, S. D., Chapuis, J., Wood, G., and Mendez, P. F. 2014. Non-wetting behavior of tungsten carbide powders in nickel weld pool: New loss mechanism in GMAW overlays. Science and Technology of Welding and Joining 19: 133-141. DOI: https://doi.org/10.1179/1362171813Y.00 00000178

21. Siewert, E. 2014. Experimentelle Analyse des Elektrodenwerkstoff-übergangs beim Metallschutzgasschweißen mit gepulstem Schweißstrom (Experimental analyses of the metal transfer in pulsed GMAW). PhD dissertation, Munich, Germany, Universität der Bundeswehr München.

KARSTEN GÜNTHER (karsten.guenther @tu-ilmenau.de) and JEAN PIERRE BERGMANN are with the Dept. of Production Technology, and CHEN ZHANG, MAIK ROSENBERGER, and GUNTHER NOTNI are with the Dept. of Quality Insurance and ImageProcessing, Ilmenau University of Technology, Ilmenau, Germany. 